\title{
Relationship between Burden of Caring for Older Adult Patients with Chronic Diseases and Family Caregivers Health Status
}

\author{
Soad Hassan Abd Elhameed, Lecturer \\ Gerontological Nursing, Faculty of Nursing, Mansoura University \\ Raefa Refaat Alam, Lecturer \\ Gerontological Nursing, Faculty of Nursing, Mansoura University
}

\begin{abstract}
Family caregivers play an essential role in caring for older adults with chronic diseases. People with multiple chronic diseases are responsible for the greatest burden on their caregivers, which in turn will affect significantly their life. Objective: To determine the relationship between burden of caring for older adult patients with chronic diseases and family caregivers' health status. Settings: The study was carried out in the outpatient clinics of Mansoura General Hospital, Mansoura University Specialized Medical Hospital, Mansoura Main University Hospital, Mansoura New General Hospital and Mansoura University Oncology center. Subjects: The study subjects included 186 older adult patients aged 60 years and more, diagnosed with one or more chronic diseases and their family caregivers aged more than 18 years. Tools: Data was collected using four tools, socio demographic and clinical data structured interview schedule, Katz and Akpom Scale, the Zarit Burden Interview and the Short Form-36 Health Survey. Results: Nearly three quarter (74.7\%) of the caregivers reported mild to moderate caregiving burden and $21.5 \%$ of them had severe caregiving burden. A lower mean total score of the physical and mental health status was found among family caregivers. Conclusion: Caregivers' burden increases by increasing dependency of the older adult patients. A positive direct relationship was found between caregivers' burden and their mental health status. Also, between their physical and mental health status. Recommendations: Develop a guideline to help caregivers of patients with chronic diseases to care for their patients at home. This will help them to cope with the burden of caring and manage stress associated with it. Also, teach caregivers about the available community services, such as respite care and adult day care centers which may help to decrease caregivers stress and burden.
\end{abstract}

Keywords: Family caregivers, Caregiving burden, Older adult, Chronic diseases, Health status.

\section{Introduction}

Family caregiving is defined as "the wide range of unpaid care provided in response to illness or functional impairment to a chronically ill or functionally impaired older family member, partner, friend, or neighbour that exceeds the support usually provided in family relationship"(1). Family caregivers play a major role in caring for older adult patients with chronic diseases. The needs of these patients are varied and may include assistance with medication, transportation, activities of daily living, social and emotional support. In addition, families may be influenced by other stressors, such as changes in roles, employment and disruptions in schedules ${ }^{(2)}$. All these factors result in caregiver burden. The term caregiver burden is commonly used to describe the financial, physical, and psychosocial problems that members experience when caring for older adults who are impaired or suffering from illness. 
Family caregivers who experience greater caregiving burden have been found to report more health problems ${ }^{(3,4)}$.

Chronic illness can be very challenging, demanding and stressful for both care recipients and people giving the care. This means that, the need for health care professionals in this field will increase drastically. With the growing number of older people with chronic diseases and with the shift from inpatient to outpatient care, the significance of informal caregivers continue to increase ${ }^{(5,6)}$. It is reported that eighty percent of the non-institutionalized older adults have one or more chronic health problems or disabilities ${ }^{(7,8)}$. Most likely people with multiple chronic diseases are responsible for the greatest burden of disease in many countries and their cost and prevalence will increase in the future as the population ages. Therefore, family members take upon themselves the considerable responsibilities, stress associated with providing adequate care and supervision for their older relatives. In addition, the family caregivers are playing an increasingly important role in enabling older adults to continue living in community settings ${ }^{(7)}$.

Previous researches reported that $85 \%-95 \%$ of family caregivers are untrained and often lack sufficient caregiving knowledge and skills. Therefore, the caregivers have to be competent and compassionate with the ill person as they experience the long, painful and distressing journey along with the care recipients and their illness ${ }^{(5,9)}$. They also have to deal with the stress and coping personally along with the chronically ill. Nurses and other health care professionals need to encourage caregivers to adopt a healthy lifestyle to maintain their own physical and mental wellbeing. Healthy lifestyle can increase resistance to stress and strength their physical and mental health ${ }^{(10)}$. Moreover, the benefits of caregiving can be maximized and the drawbacks minimized by proper intervention and guidance from healthcare professionals.

\section{Aim of the Study}

To determine the relationship between burden of caring for older adult patients with chronic diseases and family caregivers' health status.

\section{Research Question:}

What is the relationship between family caregivers' burden in caring for older adult patients with chronic diseases and their health status?

\section{Operational Definition:}

Health status, in the present study, was evaluated in terms of physical and mental health status.

\section{Materials and Method}

\section{Materials}

Design: A descriptive, cross-sectional research design was used.

Settings: The study was conducted in the outpatient clinics of Mansoura General Hospital, Mansoura University Specialized Medical Hospital, Mansoura Main University Hospital, Mansoura New General Hospital and Mansoura University Oncology center.

Subjects: The study Subjects comprised two groups; older adults patients with chronic diseases and their caregivers. These were selected from the above settings. The sample size was calculated using SPSS sample calculator with the following assumption: Alpha error $=0.05$, study power $=80 \%$ and the expected prevalence of sever caregiver burden $=64 \%$. The minimal sample size is 100 patients and their caregivers. Therefore, 186 older adult patients and their caregivers (186) were included in the study. They fulfill the following criteria:

a) Patients aged 60 years and more, diagnosed with one or more chronic diseases such as cardiovascular disease, cancer, hypertension, diabetes mellitus, 
renal disease and liver disease, able to communicate and accept to participate in the study.

b) Family caregivers aged 18 years and more, responsible for providing direct care for the older adult patients, able to communicate and willing to participate in the study.

Tools: In order to collect the necessary information for the study four tools were used:

\section{Tool I: Socio demographic and clinical data structured interview schedule}

It was developed by the researchers after reviewing literature and included two parts:

Part I: Data about older adult patients: it includes their socio-demographic characteristics such as age, sex, marital status, level of education, occupation, monthly income and health history (e.g. type and duration of chronic disease).

Part II: Data about caregivers: it includes their socio-demographic characteristics such as age, sex, level of education, occupation, marital status, health history (e.g. presence of disease), relation with the older adults, availability of another caregiver, period of caregiving and number of daily hours in giving care to the older adult patients.

\section{Tool II: Katz and Akpom Scale}

This scale was developed by Katz and Akpom (1976) $)^{(11)}$, it is originally developed to measure functional status of older adults and those with chronic disease. It was translated into Arabic language and validated by Melis and El Shazly (1999) ${ }^{(12)}$. The scale includes six activities of daily living namely, grooming, toileting, eating, dressing, bathing and mobility. The activities are measured and scored according to the individuals' actual performance. A score from one to three was assigned to each level of dependency, which one indicates that the person is independent in performing the activity, two indicates that the person performs the activity with assistance, while a score of three indicates that the person is totally dependent. The total score of this scale is 18 and is classified as follows a total score of 6 means that the person is independent, from 7 to 12 partially dependent, and from 13 to 18 totally dependent.

\section{Tool III: Zarit Burden Interview (ZBI)}

The Zarit Burden Interview was developed by Zarit et al. $(1980)^{(13)}$. It provides a global, unidimensional measure of care giving burden. The ZBI consists of 22 -item reflecting the respondent's areas of concern such as health, social, and personal life; financial situation; emotional wellbeing; and interpersonal relationships. Scoring of the items is made using a 5-point likert scale ranging from zero (Never) to four (Nearly Always). The total score of $\mathrm{ZBI}$ is 88 and is classified as follows 0 to $20=$ little or no burden, 21 to $40=$ mild to moderate burden, 41 to $60=$ moderate to severe burden, and 61 to $88=$ severe burden. The greater the total score, the greater the burden.

Tool IV: Short Form-36 Health Survey (SF-36):

The Short Form-36 Health Survey was developed by Ware and Sherbourne $(1992)^{(14)}$ and translated into Arabic and tested for its validity and reliability by Hassan $(2014)^{(15)} \quad(r=0.86)$. The SF-36 Health Survey is a generic outcome measure designed to examine a person's perceived health status and has proven to be useful in survey of general and specific populations and in estimating burden of diseases. It includes one multi-item scale that measures eight domains of health: physical functioning, role limitations due to physical health, bodily pain, general health perceptions, vitality, social functioning, role limitations due to emotional problems, and mental health. The SF-36 can also be divided into two aggregate summary that measures the physical component summary (PCS) and the mental health component summary (MCS). All scores are transformed into a $0-100$ scale on the assumption that 
each question carries equal weight with 100 representing the highest level of functioning possible.

\section{Method}

- Official letters were issued to the directors of Mansoura University Specialized Medical Hospital, Mansoura Main University Hospital, Mansoura General Hospital, Mansoura New General Hospital and Mansoura University Oncology center to obtain their approval to carry out the study.

- Study tool I (socio demographic and clinical data structured interview schedule) was developed by the researchers after reviewing the relevant literature.

- Tool III (The Zarit Burden Interview) was translated into Arabic language by the researchers and tested for reliability using test retest method. This tool was applied to 20 older adults and their caregivers selected from Mansoura University Oncology Center and reapplied 2 weeks later. The reliability was assured by means of Cronbach's alpha $(\mathrm{r}=0.88)$.

- The Arabic versions of the study tool II (Katz and Akpom Scale) and IV (Short Form-36 Health Survey) were used.

- Study tools were revised by 5 experts in the fields of Gerontological Nursing Faculty of Nursing Alexandria University, Medical Surgical Nursing and Psychiatric Nursing Faculty of Nursing Mansoura University and Community health Medicine Faculty of Medicine Mansoura University, to test its content validity and feasibility and the necessary modifications were done.
- A pilot study was carried out on 10 older adult patients and their family caregivers selected from the outpatient clinics in Mansoura Oncology Center before starting the data collection to ascertain the clarity and applicability of the study tools, also to estimate the approximate time needed to complete the study tools. In light of the findings of the pilot study, the necessary modifications were done. Then, the tools were put into their final form. The patients and their family caregivers were not included in the study sample.

- According to the schedule designed by the researchers, each older adult patient and his family caregiver were interviewed individually after explaining the purpose of the study then the necessary data was collected using the study tools.

- The researchers collected data, three days a week on Saturday, Monday and Thursday from the study settings from 10 am to $2 \mathrm{pm}$ for a period of five months. The interview time of each family caregiver ranged from 30-45 minutes.

- Data collection started from December 2014 to the end of April 2015 .

\section{Ethical considerations:}

Verbal consent was obtained from the study subjects after explanation of the purpose of the study. Anonymity, privacy and confidentiality of the collected data of each older adult and each family caregiver was assured throughout the study.

\section{Statistical Analysis}

Statistical analysis was performed using the Statistical Package of Social Science (SPSS) software version 16.0. The 0.05 and 0.01 levels were used as the cut off value 
for statistical significance and the following statistical measures were used: descriptive statistics (count \& percentage, minimummaximum, mean \&standard deviation) and analytical statistics (Pearson's correlation test, Anova test and Independent sample ttest).

\section{Results}

Table (1) shows the socio demographic characteristics of the older adult patients. Of the 186 older adult patients included in the study, $62.9 \%$ were 60 to less than 70 years old with a mean of $67.29 \pm 6.3$ years. Females constituted $68.8 \%$ and more than half $(55.9 \%)$ were married. Illiteracy was prevailing among $76.9 \%$ and $60.7 \%$ of the elders were housewives. $39.2 \%$ of the older adult patients reported having enough income and about $79 \%$ of them live in rural area.

Table (2) represents that $45.7 \%$ of the patients suffered from two chronic diseases, $28.5 \%$ from three and more chronic diseases and the rest $(25.8 \%)$ from only one chronic disease. In addition, $64.5 \%$ of the studied older adult patients suffered from hypertension followed by cancer $55.4 \%$ and diabetes $45.7 \%$. The duration of the disease ranged from one to more than 10 years with a mean of $3.23 \pm 2.76$. The majority $(84.9 \%)$ of the patients suffered from the disease since less than 5 years. Those who reported previous hospitalization amounted to $43.0 \%$.

Figure (1) shows the functional status of the older adult patients. It appears that $68.3 \%$ were independent, $25.3 \%$ needs assistance and $6.4 \%$ were totally dependent.

Table (3) reveals that the age of $50.6 \%$ of the studied caregivers ranged from 30 to less than 45 years and $29 \%$ were more than 45 years old with a mean of $40.71 \pm 11.52$ years. Females constituted $69.4 \%$ and $81.7 \%$ of them were married. Higher level of education (secondary and university) was reported by $72.1 \%$. Housewives constituted $54.9 \%$ and $40.3 \%$ were working.
Table (4) shows that $84.4 \%$ of the studied caregivers do not complain from any disease. The persons responsible for giving the care to the patients was mainly one of the siblings for $48.9 \%$, husband or wife $15.1 \%$ and brother or sister $14.0 \%$. In relation to caregivers who live with the older adult patients in the same house, it was noticed that $67.2 \%$ live with them. In addition, $74.7 \%$ of the caregivers reported availability of another caregiver to help. It appears that $40.3 \%$ of the caregivers provide care for the older adults since less than 1 year and $37.1 \%$ were caring from 1 to less than 3 years with a mean of $2.79 \pm 2.65$ years. $43.5 \%$ of the caregivers spend from 2 to less than 4 hours daily in caring for the older adult patients with a mean of $3.97 \pm 1.67$ hours.

Figure (2) shows that $47.8 \%$ of the studied caregivers reported moderate caregiving burden and $21.5 \%$ reported severe caregiving burden. The mean total burden score was $48.12 \pm 14.49$.

Table (5) represents that caregivers had lower mean total score of physical and mental health status except for emotional wellbeing and pain domains. The mean physical and mental health total score was $36.53 \pm 15.23$ and $44.47 \pm 17.19$ respectively. A statistically significant relation was found between physical and mental health status mean total score $(\mathrm{P}=0.000)$.

Table (6) shows a significant relation between age of the older adults and caregivers burden $(\mathrm{P}=0.000)$, physical $(\mathrm{P}=0.002)$ and mental health status $(\mathrm{P}=0.054)$. In addition, a statistically significant relation was found between total mean score of caregivers burden and older adult patients level of education ( $\mathrm{P}=0.000)$, occupation before retirement $(\mathrm{P}=0.000)$, income $(\mathrm{P}=0.000), \quad$ functional status $(\mathrm{P}=0.002)$ and duration of chronic diseases $(\mathrm{P}=0.000)$. The total mean scores increases with increasing dependency. As well, caregivers mental health status mean total score had significant relation with the older adults sex $(\mathrm{P}=0.008)$. 
Table (7) reveals no statistical significant relation between mean total scores of caregivers' burden and their sociodemographic characteristics.

Table (8) shows a significant relation between caregivers burden and caregivers relation to older adults $(\mathrm{P}=0.002)$, period of caregiving $(\mathrm{P}=0.026)$ and daily hours of caring $(\mathrm{P}=0.002)$. Moreover, a significant relation was found between caregivers mental health status and period of caregiving $(\mathrm{P}=0.024)$.

Table (9) represents a strong positive correlation between caregiving burden and caregivers mental health status $(\mathrm{P}=0.004)$ and between caregivers physical and mental health status $(\mathrm{P}=0.000)$.

\section{Discussion}

Caring for older adults with chronic diseases may involve additional challenges, which may put family caregivers at particularly high risk of burden. Chronic illness not only has an impact on people suffering from the illness but also significantly affects the caregiver's life ${ }^{(5)}$. Therefore, the aim of this study was to determine the relationship between burden of caring for older adult patients with chronic diseases and family caregivers' health status.

The present study revealed that nearly three quarter of the studied caregivers had mild or moderate burden (figure 2). The calculated mean burden total score $(48.12 \pm 14.49)$ of the caregivers in this study was higher in comparison to those reported in other studies done in Egypt by Salama et al. $(2012)^{(7)}(35 \pm 14.1)$ and in China by Young et al. $(2012)^{(16)}(27.3 \pm 15.0)$. This difference may be related to the cultural experiences inherent to caring for older adults and the characteristics of the study subjects. Moreover, the results of the present study showed a statistical significant relation between caregivers' burden and older adult patients' functional status (table 6) where the caregivers burden increased with increasing dependency of the older adult patients. This result may be due to the decline in physical functioning occurring with aging, and older adult patients with chronic diseases become more dependent on others to meet their needs therefore, increased caregiver burden is expected. This result supports the result of Salama et al. $(2012)^{(7)}$ in Egypt who noticed that caregiver burden is affected by the degree of the care recipient's dependency for carrying out tasks of daily life. In addition, illiteracy of older adult patients and low income affected significantly caregivers' burden (table 6). This may be explained by the fact that the less educated older adult patients have inadequate knowledge and poor coping strategies for managing their chronic disease. This result contradicts those of other studies done in USA by Garlo et al. (2010) ${ }^{(18)}$ and in Brazil by Loureiro et al. $(2013)^{(19)}$. Also, the present study revealed a statistical significant relation between caregivers burden and age of the older adults (table 6). This result may be explained by the fact that older adults experience both physical and psychosocial changes with ageing, chronic diseases, and increase in their needs, which may lead to increasing caregivers' burden. This result is in agreement with a study done by Papastavrou et al. (2009) ${ }^{(17)}$ in Cyprus who found that old age is a predictor of caregiver burden.

There is evidence of the negative impact of caregiving on the physical and mental health status of the caregivers ${ }^{(20)}$. The results of the present study showed that, there is decreases on both physical and mental health status mean total score of the caregivers (table 5). This result may be justified by the fact that caregivers caring for patients with chronic diseases are at higher risk to loose their physical strength and deterioration of their health while meeting patients needs this in turn will lead to burden. Moreover, a statistical significant correlation between caregiver burden and their physical and mental health status was found (table 9). The results of this study 
demonstrated that caregiver burden is a positive predictor of mental health status and vice versa. This denotes the importance to assess caregiver's physical and mental health as it helps in exploring their burden, which can have an impact on the patient's illness and their function. This result is consistent with the results of Evci et al. $(2012)^{(21)}$ in Turkey who showed that there is a correlation between caregiver burden and general psychological health.

The present study showed that, caregivers with low level of education suffered from high burden, low physical and mental health status but the difference was not statistically significant (table 7). The same results were reported by Limpawattana et al. (2012) $)^{(22)}$ in Thailand. Moreover, caregivers who reported having not enough income had higher mean score of burden and lower mean score of physical and mental health status than those with enough income and the differences were significant except with mean score of mental health (table 7). This result may be related to the fact that the majority of older adults had not enough income and live in rural areas, therefore caregivers were more likely to feel the burden of expenses of treatment, transportation and follow up visits. Also, low income can influence caregivers' social function such as leisure activities resulting in more caregiver burden and physical and psychological problems. This result supports those of other studies done in Egypt by Salama et al. (2012) ${ }^{(7)}$ and Ali $(2015)^{(20)}$ who noticed that income was a predictor of burden.

The study revealed that, the caregiving to older adults with chronic diseases was mainly provided by siblings (table 5). This result may be due to the presence of aged wife who suffers from chronic illness and who cannot provide care for her husband and by tradition, the other family members especially daughters and daughters-in-law take the responsibility for caring for older adults. The same finding was reported by different researches ${ }^{(21,23)}$. While, other references reported that nearly half of the caregivers for older adults are wives ${ }^{(16)}$. A statistical significant relation was found between caregiver burden and caregiver relation with the older adults (table 8). In addition, More than two third of the studied caregivers live with the older adult patients in the same house (table 4) but no statistically significant difference found between caregivers burden and living with the patients (table 8). This result may due to the presence of extended family in Egypt especially in the rural areas. The same results was reported by Ali $(2015)^{(20)}$ study in Egypt.

The present study revealed that nearly two thirds of the studied older adults' patients suffered from hypertension followed by cancer and diabetes (table 2 ). This finding may be explained by the fact that chronic diseases and co-morbidities increase with advancing age. In addition, a statistical significant relation was found between mean total score of caregivers' burden, their physical health status and duration of the disease among older adults (table 6). This result is in the same line with Ibrahim $(2013)^{(24)}$ study in Egypt, who found that more than $50 \%$ of individuals older than 60 years suffered from hypertension.

According to the results of some studies, approximately $60-77 \%$ of caregivers were females $^{(25,26)}$ and this is the same in the present study (table 3). Moreover, females were more likely to perceive higher burden than male. This finding may be justified by the fact that the traditional role of caregiving is often expected to be performed by females, the multiple caring roles of women and other gender-related challenges, such as spending more time with older adult patients than men caregivers. Moreover, receiving less assistance with caregiving tasks and spending more time on intensive personal care and domestic chores. Despite this, the difference between caregivers' sex and burden was not statistically significant 
(table 7). This result is consistent with the previous studies of Limpawattana et al. $(2012)^{(22)}$ in Thailand and Loureiro et al. $(2013)^{(19)}$ in Brazil.

Regarding the availability of another person to help the caregivers in caring for the older adult, the result of the present study showed that caregivers who have no help had lower mean score of burden than those who have someone to help in the care of the older adults' patient (table 8). This is because the caregiver may experience extra burden from caring for their children, housekeeping and working outside the home. Also, no statistical significant relation was found between caregivers' burden, physical and mental health status and availability of another person to help in caring for the older adult. This results is in agreement with a study done in the United States of America by Kim et al. (2012) ${ }^{(27)}$ and a study done in Malaysia by Mahadevan et al. (2013) ${ }^{(28)}$ who reported that the number of helpers and perceiving support from others did not have a significant effect on decreasing caregiver burden or mental health.

Effective gerontological nursing recognizes that the health of all family members must be maintained and promoted $^{(16)}$. Nurses and other healthcare teams should acknowledge informal caregiver and older adult patient as one unit of care and need to balance patients and caregivers' need for information, support and sense of medical partnership. Therefore, the caregivers' physical, emotional and social health must be evaluated periodically to ensure that they are competent to provide the required services. These findings highlight the importance of early assessment, nursing diagnosis and potential interventions to reduce family caregivers' burden, physical and psychological distress and help them to cope with their caregiving role.

\section{Conclusion}

Based on the results of the present study, it can be concluded that, caregivers burden is common among the family caregivers who care for older adult patients with chronic diseases. This burden increases by increasing dependency of the older adult patients. The burden affected significantly the physical and mental health status of the caregivers. In addition, a positive direct correlation was found between caregivers' burden and their mental health status and between physical and mental health status of the caregivers.

\section{Recommendations}

In the light of the findings, the following recommendations are suggested:

1- Develop a guideline to help caregivers of patients with chronic diseases to care for their patients at home. This will help them to cope with the burden of caring and manage stress associated with it.

2- Families should be included in the plan of care of the older adult patients as this will help in increasing their knowledge about the required care and avoid their stress and in turn decrease the burden facing them.

3- Teach caregivers about the available community services, such as respite care and adult day care centers, which may help to decrease caregivers stress and burden. 
4- Special attention should be given to family caregivers to identify early those at risk to develop burden. This could be achieved through emphasizing the importance of their attendance of health classes about changes associated with old age and care of chronic diseases, and inform them about the available services that can help them.

5- Counseling caregivers about problems faced in caring for their patients as well as provide them with adequate knowledge and skills to help them to cope with the present condition. As well as, it is important to assess periodically the caregiver burden in order to institute appropriate intervention to help them to overcome the burden whether physical or psychological, which may have an impact on their efficient functioning. 
Table (1): Distribution of the studied older adult patients according to their sociodemographic characteristics

\begin{tabular}{|c|c|c|}
\hline Sociodemographic characteristics & N (186) & $\%$ \\
\hline \multicolumn{3}{|l|}{ Age (in years): } \\
\hline $60-$ & 82 & 44.1 \\
\hline $65-$ & 35 & 18.8 \\
\hline $70-$ & 31 & 16.7 \\
\hline $75+$ & 38 & 20.4 \\
\hline \multicolumn{3}{|c|}{ Mean $\pm \mathrm{SD}=67.29 \pm 6.30$} \\
\hline Sex: & & \\
\hline Female & 128 & 68.8 \\
\hline Male & 58 & 31.2 \\
\hline \multicolumn{3}{|l|}{ Marital status: } \\
\hline Married & 104 & 55.9 \\
\hline Widowed & 75 & 40.3 \\
\hline Divorced & 5 & 2.7 \\
\hline Single & 2 & 1.1 \\
\hline \multicolumn{3}{|l|}{ Level of education: } \\
\hline Illiterate & 143 & 76.9 \\
\hline Secondary education & 21 & 11.3 \\
\hline Read \& write & 16 & 8.6 \\
\hline University education & 6 & 3.2 \\
\hline \multicolumn{3}{|l|}{ Occupation before retirement: } \\
\hline Not working & 113 & 60.7 \\
\hline Working & 73 & 39.3 \\
\hline \multicolumn{3}{|l|}{ Monthly income: } \\
\hline Not enough & 113 & 60.8 \\
\hline Enough & 73 & 39.2 \\
\hline \multicolumn{3}{|l|}{ Residence: } \\
\hline Rural & 147 & 79.0 \\
\hline Urban & 39 & 21.0 \\
\hline
\end{tabular}


Table (2): Distribution of the studied older adult patients according to their clinical data

\begin{tabular}{|c|c|c|}
\hline Medical history & No (186) & $\%$ \\
\hline \multicolumn{3}{|l|}{ Number of chronic diseases: } \\
\hline One & 48 & 25.8 \\
\hline Two & 85 & 45.7 \\
\hline Three or more & 53 & 28.5 \\
\hline \multicolumn{3}{|l|}{ Type of chronic disease \#: } \\
\hline Hypertension & 120 & 64.5 \\
\hline Cancer & 103 & 55.4 \\
\hline Diabetes mellitus & 85 & 45.7 \\
\hline Renal disease & 19 & 10.2 \\
\hline Cardiovascular disease & 17 & 9.1 \\
\hline Liver disease & 11 & 5.9 \\
\hline Others (respiratory and psychiatric) & 7 & 3.8 \\
\hline \multicolumn{3}{|l|}{ Duration of disease: } \\
\hline $1<3$ years & 134 & 72.0 \\
\hline $3<5$ years & 24 & 12.9 \\
\hline $5<10$ years & 13 & 7.0 \\
\hline 10 years and more & 15 & 8.1 \\
\hline \multicolumn{3}{|c|}{ Mean $\pm \mathrm{SD}=3.23 \pm 2.76$} \\
\hline \multicolumn{3}{|l|}{ Previous hospitalization: } \\
\hline No & 106 & 57.0 \\
\hline Once & 52 & 28.0 \\
\hline Twice or more & 28 & 15.0 \\
\hline
\end{tabular}

\# More than one answer was given 


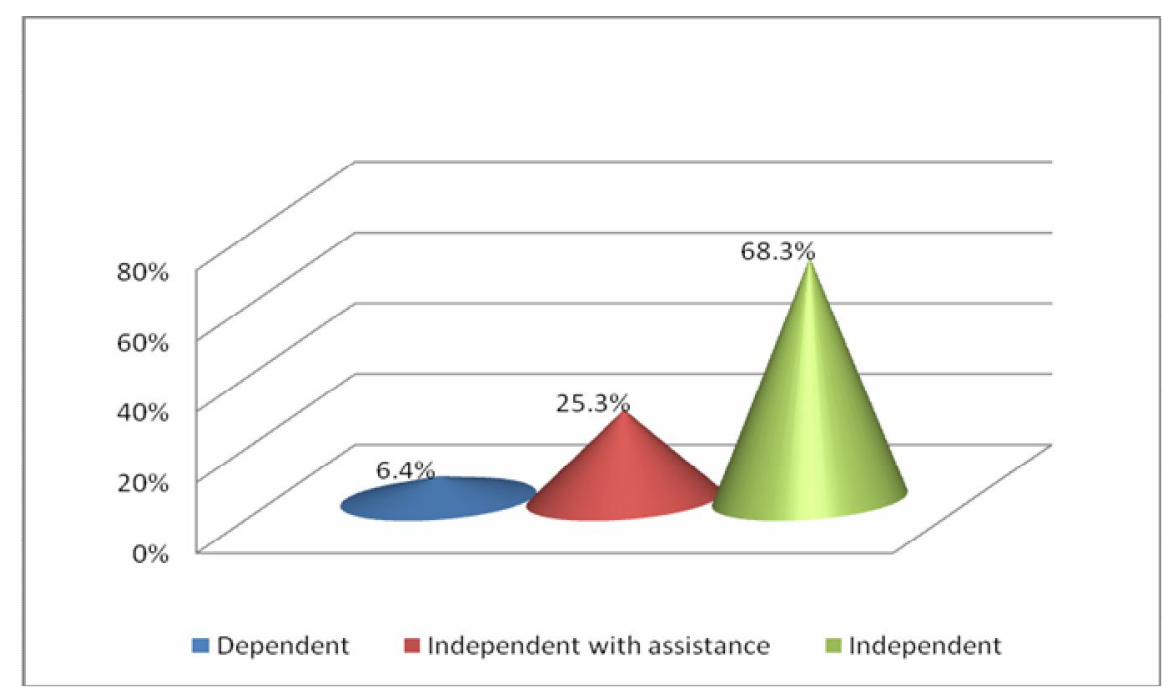

Figure (1): Patients functional status

Table (3): Distribution of the studied caregivers according to their sociodemographic characteristics

\begin{tabular}{|c|c|c|}
\hline Sociodemographic Characteristics & N (186) & $\%$ \\
\hline $\begin{array}{l}\text { Age (in years): } \\
18- \\
30- \\
45+\end{array}$ & $\begin{array}{l}38 \\
94 \\
54\end{array}$ & $\begin{array}{l}20.4 \\
50.6 \\
29.0 \\
\end{array}$ \\
\hline \multicolumn{3}{|c|}{ Mean $\pm \mathrm{SD}=40.71 \pm 11.52$} \\
\hline $\begin{array}{l}\text { Sex : } \\
\text { Female } \\
\text { Male }\end{array}$ & $\begin{array}{c}129 \\
57\end{array}$ & $\begin{array}{l}69.4 \\
30.6\end{array}$ \\
\hline $\begin{array}{l}\text { Marital status : } \\
\text { Married } \\
\text { Single } \\
\text { Widow } \\
\text { Divorced }\end{array}$ & $\begin{array}{c}152 \\
25 \\
5 \\
4\end{array}$ & $\begin{array}{c}81.7 \\
13.4 \\
2.7 \\
2.2\end{array}$ \\
\hline $\begin{array}{l}\text { Level of education : } \\
\text { Secondary } \\
\text { University } \\
\text { Illiterate } \\
\text { Read \& write } \\
\text { Occupation : } \\
\text { Not working } \\
\text { Working }\end{array}$ & $\begin{array}{c}100 \\
35 \\
34 \\
17 \\
\\
111 \\
75\end{array}$ & $\begin{array}{c}53.8 \\
18.8 \\
18.3 \\
9.1 \\
\\
59.7 \\
40.3\end{array}$ \\
\hline
\end{tabular}


Table (4): Distribution of the studied caregivers according to their characteristics

\begin{tabular}{|c|c|c|}
\hline Caregivers characteristics & N (186) & $\%$ \\
\hline \multicolumn{3}{|l|}{ Presence of disease: } \\
\hline No & 157 & 84.4 \\
\hline Yes & 29 & 15.6 \\
\hline \multicolumn{3}{|c|}{ Relationship with the older adult: } \\
\hline Siblings & 91 & 48.9 \\
\hline Husband / wife & 28 & 15.1 \\
\hline Brother / sister & 26 & 14.0 \\
\hline A relative & 23 & 12.3 \\
\hline Daughter in law & 18 & 9.7 \\
\hline \multicolumn{3}{|l|}{ Living in the same house : } \\
\hline Yes & 125 & 67.2 \\
\hline No & 61 & 32.8 \\
\hline \multicolumn{3}{|c|}{ Availability of another caregiver: } \\
\hline Yes & 139 & 74.7 \\
\hline No & 47 & 25.3 \\
\hline \multicolumn{3}{|l|}{ Period of caregiving: } \\
\hline Less than 1 year & 75 & 40.3 \\
\hline $1<3$ years & 69 & 37.1 \\
\hline 3 years and more & 42 & 22.6 \\
\hline \multicolumn{3}{|c|}{ Mean $\pm S D=2.79 \pm 2.65$} \\
\hline \multicolumn{3}{|l|}{ Daily hours of caring: } \\
\hline $2<4$ hours & 81 & 43.5 \\
\hline $4<6$ hours & 69 & 37.1 \\
\hline 6 hours and more & 36 & 19.4 \\
\hline
\end{tabular}




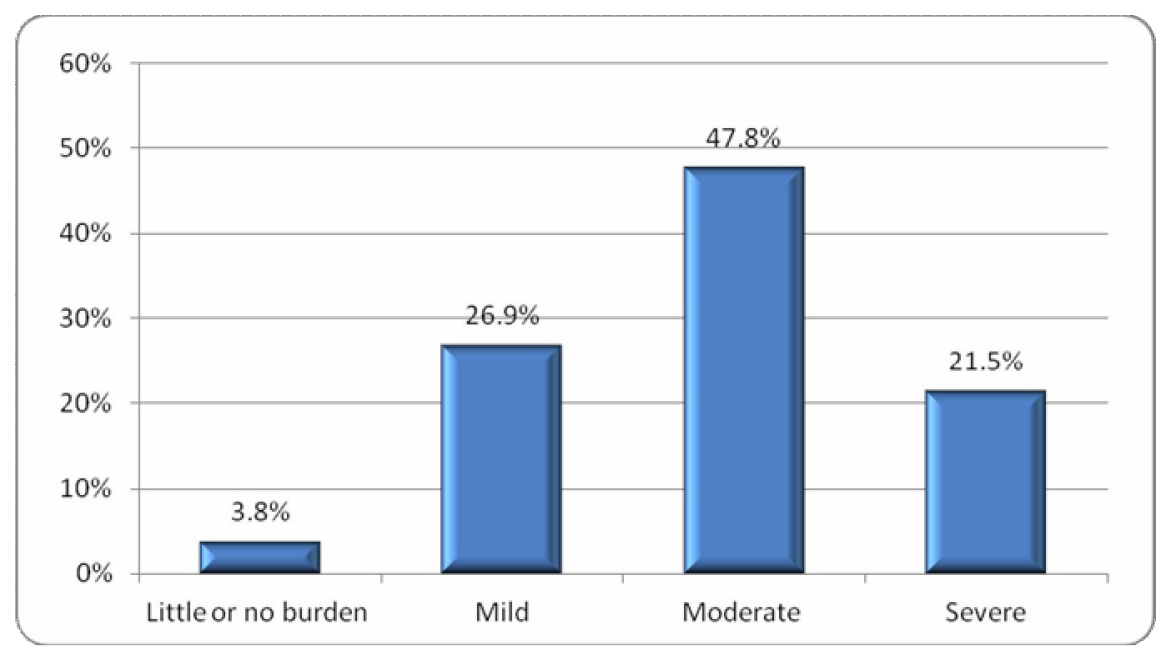

Figure (2): Caregivers burden

Table (5): Distribution of the studied caregivers according to their physical and mental health status

\begin{tabular}{||l|c|c|c||}
\hline Health status (SF-36) & Min-Max & Mean \pm SD & P-value \\
\hline $\begin{array}{l}\text { Physical health domains: } \\
\text { 1- General health }\end{array}$ & $0-92$ & $42.11 \pm 19.19$ & \\
2- Physical functioning & $0-80$ & $24.17 \pm 19.82$ & \\
3- Role limitation due to & $0-100$ & $28.23 \pm 33.84$ & $\mathrm{P}=0.000^{*}$ \\
$\quad \begin{array}{l}\text { physical health } \\
\text { 4- Pain }\end{array}$ & $10-100$ & $50.15 \pm 24.83$ & \\
\hline $\begin{array}{l}\text { Physical health total score } \\
\text { Mental health domains: }\end{array}$ & $8-75$ & $36.53 \pm 15.23$ & \\
1- Emotional wellbeing & $9-100$ & $60.85 \pm 15.10$ & \\
2- Role limitation due to & $0-100$ & $29.80 \pm 38.60$ & \\
$\quad$ emotional problems & $15-80$ & $37.42 \pm 18.67$ & $\mathrm{P}=0.000 *$ \\
3- Energy & $0-100$ & $48.76 \pm 22.62$ & \\
4- Social functioning & $15-86$ & $44.47 \pm 17.19$ & \\
\hline Mental health total score & &
\end{tabular}

*Significance at $\mathrm{p} \leq 0.05$ 
Table (6): Relationship between patients' socio-demographic characteristics, duration and number of diseases, functional status and caregivers' burden, physical and mental health status

\begin{tabular}{|l|c|c|c||}
\hline $\begin{array}{l}\text { Patients } \\
\text { sociodemographic } \\
\text { characteristics }\end{array}$ & Caregiving burden & $\begin{array}{c}\text { Caregivers physical } \\
\text { health status }\end{array}$ & $\begin{array}{c}\text { Caregivers mental } \\
\text { health status }\end{array}$ \\
\hline Age & $\mathrm{F}=6.757(0.000)^{*}$ & $\mathrm{~F}=5.200(0.002)^{*}$ & $\mathrm{~F}=2.598(0.054)$ \\
\hline Sex & $\mathrm{T}=1.444(0.150)$ & $\mathrm{T}=1.285(0.200)$ & $\mathrm{T}=2.701(0.008)^{*}$ \\
\hline Marital status & $\mathrm{F}=1.477(0.222)$ & $\mathrm{F}=1.057(0.369)$ & $\mathrm{F}=2.010(0.114)$ \\
\hline Level of education & $\mathrm{F}=7.120(0.000)^{*}$ & $\mathrm{~F}=2.249(0.084)$ & $\mathrm{F}=1.105(0.348)$ \\
\hline $\begin{array}{l}\text { Occupation before } \\
\text { retirement }\end{array}$ & $\mathrm{F}=9.448(0.000)^{*}$ & $\mathrm{~F}=1.361(0.249)$ & $\mathrm{F}=2.020(0.094)$ \\
\hline Monthly income & $\mathrm{F}=13.087(0.000)^{*}$ & $\mathrm{~F}=1.270(0.283)$ & $\mathrm{F}=0.318(0.728)$ \\
\hline Residence & $\mathrm{T}=1.769(0.078)$ & $\mathrm{T}=1.549(0.123)$ & $\mathrm{T}=1.054(0.293)$ \\
\hline $\begin{array}{l}\text { Duration of disease } \\
\text { Number of chronic } \\
\text { diseases }\end{array}$ & $\mathrm{F}=5.090(0.002)^{*}$ & $\mathrm{~F}=0.107(0.956)$ & $\mathrm{F}=0.107(0.956)$ \\
\hline Functional status & $\mathrm{F}=19.150(0.000)^{*}$ & $\mathrm{~F}=1.241(0.291)$ & $\mathrm{F}=0.729(0.484)$ \\
\hline \hline
\end{tabular}

*Significance at $\mathrm{p} \leq 0.05$

Table (7): Relationship between caregivers' socio-demographic characteristics, caregiving burden and their physical and mental health status

\begin{tabular}{|c|c|c|c|}
\hline $\begin{array}{l}\text { Sociodemographic } \\
\text { Characteristics }\end{array}$ & Test (P-value) & $\begin{array}{c}\text { Caregivers physical } \\
\text { health status } \\
\text { Test (P-value) }\end{array}$ & $\begin{array}{c}\text { Caregivers mental } \\
\text { health status } \\
\text { Test (P-value) }\end{array}$ \\
\hline Age & $\mathrm{F}=1.614(0.202)$ & $\mathrm{F}=0.578 \quad(0.562)$ & $\mathrm{F}=2.041 \quad(0.133)$ \\
\hline Sex & $\mathrm{T}=1.976(0.050)$ & $\mathrm{T}=1.202(0.231)$ & $\mathrm{T}=0.388 \quad(0.699)$ \\
\hline Marital status & $\mathrm{F}=0.916(0.434)$ & $\mathrm{F}=0.197 \quad(0.898)$ & $\mathrm{F}=0.094(0.963)$ \\
\hline Level of education & $\mathrm{F}=0.598 \quad(0.617)$ & $\mathrm{F}=1.038 \quad(0.377)$ & $\mathrm{F}=1.334(0.265)$ \\
\hline Occupation & $\mathrm{F}=0.266 \quad(0.767)$ & $\mathrm{F}=1.457(0.236)$ & $\mathrm{F}=0.631 \quad(0.533)$ \\
\hline
\end{tabular}

*Significance at $\mathrm{p} \leq 0.05$ 
Table (8): Relationship between caregivers' characteristics, caregiving burden and their physical and mental health status

\begin{tabular}{|c|c|c|c|}
\hline Caregivers' characteristics & $\begin{array}{c}\text { Caregiving } \\
\text { burden } \\
\text { Mean } \pm \text { SD }\end{array}$ & $\begin{array}{c}\text { Caregivers } \\
\text { physical health } \\
\text { status } \\
\text { Mean } \pm \text { SD }\end{array}$ & $\begin{array}{c}\text { Caregivers } \\
\text { mental health } \\
\text { status } \\
\text { Mean } \pm \text { SD }\end{array}$ \\
\hline Suffering from disease & $\mathrm{T}=0.048(\mathrm{P}=0.962)$ & $\mathrm{T}=0.925(\mathrm{P}=0.356)$ & $\mathrm{T}=1.085(\mathrm{P}=0.279)$ \\
\hline Relation with older adult & $\mathrm{F}=3.851(0.002)^{*}$ & $\mathrm{~F}=0.995(0.424)$ & $\mathrm{F}=1.586(0.166)$ \\
\hline Living with older adults & $\mathrm{T}=1.610(0.109)$ & $\mathrm{T}=0.186(0.853)$ & $\mathrm{T}=0.298(0.766)$ \\
\hline Availability of another caregiver & $\mathrm{T}=0.297 \quad(0.767)$ & $\mathrm{T}=0.036(0.972)$ & $\mathrm{T}=1.834(0.068)$ \\
\hline Period of caregiving & $\mathrm{F}=3.146(0.026)^{*}$ & $\mathrm{~F}=1.515(0.212)$ & $\mathrm{F}=3.228(0.024)^{*}$ \\
\hline Daily hours of caring & $\mathrm{F}=6.347(0.002)^{*}$ & $\mathrm{~F}=0.729(0.484)$ & $\mathrm{F}=1.763(0.174)$ \\
\hline
\end{tabular}

*Significance at $\mathrm{p} \leq 0.05$

Table (9): Correlation between caregivers burden, physical and mental health status

\begin{tabular}{||l|c|c|c||}
\hline Item & $\begin{array}{c}\text { Caregiving } \\
\text { burden }\end{array}$ & $\begin{array}{c}\text { Caregivers } \\
\text { physical health } \\
\text { status }\end{array}$ & $\begin{array}{c}\text { Caregivers } \\
\text { mental health } \\
\text { status }\end{array}$ \\
\hline Caregiving burden & $\mathbf{r}(\mathbf{P})$ & $\mathbf{r}(\mathbf{P})$ & $\mathbf{r}(\mathbf{P})$ \\
\hline Caregivers physical health status & - & $0.056 \quad(0.444)$ & $0.212 \quad(0.004)^{* *}$ \\
\hline Caregivers mental health status & - & - & $0.604 \quad(0.000)^{* *}$ \\
\hline
\end{tabular}

**. Correlation is significant at the 0.01 level (2-tailed) 


\section{References}

1. Eckman M. Lippincott's Nursing Guide to Expert Elder Care. China: Lippincott Williams\& Wilkins Company, 2011: 335-57.

2. American Cancer Society. What It Takes to Be a Caregiver. 2014. Available at: http://www.cancer.org. Accessed on: April 25, 2015.

3. Goldberg A and Rickler K. The Role of Family Caregivers for People with Chronic Illness. Journal of Medicine \& Health/Rhode Island 2011; 94 (2):41-2.

4. Miller C. Wellness in older adults. $5^{\text {th }}$ ed., USA; Lippincott William \& Wilkins Company, 2009:573.

5. Rawal G. Caregiver burden and chronic illness among aging adults: An analysis of the factors moderating levels of caregiver burden/stress in caregivers. Master Thesis. Joe C. Jackson College of Graduate of Studies and Research. Central Oklahoma University, 2014. Available at: http://proquest.umi.com. Accessed on: June 12, 2015.

6. Haley W. Family caregivers of elderly patients with cancer: Understanding and minimizing the burden of care. Journal of Support Oncol 2003; 1(2): 25-9.

7. Salama $R$ and Abou El-Soud F. Caregiver burden from caring for impaired elderly: A cross-sectional study in rural Lower Egypt. Italian Journal of Public Health 2012, 9(4):110.

8. Parchman $M$, Noel $\mathrm{P}$ and Lee $\mathrm{S}$. Primary care attributes, health care system hassles, and chronic illness. Journal of Medical Care 2005; 43: 1123-29

9. Abd Elhameed $\mathrm{S}$ and Shebl A. Impact of informal caregivers training program on geriatric patients' functional status and post-stroke depression. Journal of
Nursing and Health Science 2014; 3(4): 45-53.

10. Yarbro C, Wujcik D, Gobel B. Cancer nursing: Principles and practice. $7^{\text {th }}$ ed. USA; Jones \& Bartlett Learning, 2010: 1789: 93.

11. Katz S and Akpom C. Index of ADL: A standardized measure of biological and psychological function. International Journal of Health Science 1976; 6: 123 40.

12. Melis A and El Shazly S. Assessment of activity of daily living and mental status of elderly residing in dar Mohamed Ragab. Unpublished paper submitted to Faculty of Nursing. Alexandria University, 1999.

13. Zarit S, Reever K, and Bach-Peterson J. Relatives of the impaired elderly: Correlates of feelings of burden. Journal of Gerontologist 1980; 20(6):649-55.

14. Ware J and Sherbourne C. The MOS 36-item short form health survey (SF36): Conceptual framework and item selection. Journal of Medical Care 1992; 30: 473-83.

15. Mounir E. Effect of discharge plan on the quality of life of acute myocardial infarction among elderly patients. Unpublished Doctoral Thesis. Faculty of Nursing. Mansoura University, 2014.

16. Yang X, Hao Y, George S and Wang L. Factors associated with health-related quality of life among Chinese caregivers of the older adults living in the community: A cross-sectional study. Journal of Health and Quality of Life Outcomes 2012; 10:143.

17. Papastavrou E, Charalambous A and Tsangaris H. Exploring the other side of cancer care: The informal caregiver. European Journal of Oncology Nursing 2009; 13: 128-36. 
18. Garlo K, O'Leary R, Van Ness $\mathrm{H}$ and Fried R. Burden in caregivers of older adults with advanced illness. Journal of the American Geriatric Society 2010; 58(12): 2315-22.

19. Loureiro S, Fernandez M, Marques S, Nóbrega $\mathrm{M}$ and Rodriguez R. Burden in family caregivers of the elderly: Prevalence and association with characteristics of the elderly and the caregivers. Journal of São Paulo University School of Nursing 2013; 47(5):1133-40.

20. Ali S. Relationship between caregiving burden and psychological health status of the caregivers caring for older adults with cancer. Unpublished Master Thesis. Faculty of Nursing. Mansoura University, 2015.

21. Evci D, Ergin F, Saruhan G, Benli C, Beser E, Okur O, and Okyay $\mathrm{P}$. Prevalence and predictors of burden among family caregivers of the elderly in a Western City in Turkey: a community-based, cross-sectional study. Journal of Medicine and Medical Sciences, 2012; 3(9): 569-77.

22. Limpawattana $P, \quad$ Theeranut A, Chindaprasirt J, Sawanyawisuth K and Pimporm J. Caregivers burden of older adults with chronic illnesses in the community: A cross-sectional study. Journal of Community Health 2012; $38(1): 40-5$.

23. Eliopoulos C. Gerontological nursing. $8^{\text {th }}$ ed., USA; Lippincott Williams \&Wilkins Company, 2014: 509-16.
24. Ibrahim A, Khaled H, Mikhail N, Baraka H, and Kamel $H$. Cancer Incidence in Egypt: Results of the National Population-Based Cancer Registry Program. Journal of Cancer Epidemiology 2014; 2014:1-18.

25. Carod-Artal F, Coral L, Trizotto D and Moreira C. Burden and perceived health status among caregivers of stroke patients. Journal of Cerebrovascular Diseases 2009; 28(5):472-80.

26. Barnstorm L, Eriksson G, von Koch L and Tham K. Combined life satisfaction of persons with stroke and their caregivers: Associations with caregiver burden and the impact of stroke. Journal of Health and Quality of Life Outcomes 2011;9:1.

27. Kim H, Chang M, Rose K and Kim S. Predictors of caregiver burden in caregivers of individuals with dementia. Journal of Advanced Nursing 2012; 68(4): 846-55.

28. Mahadevan R, NikJaafar $R$, Din $S$, Ahmad N, Baharuddin A and Razali R. The stress of caregiving: A study of family caregivers of breast cancer patients receiving oncologic treatment at a Malaysian general hospital. Journal of Sains Malaysiana 2013; 42(7): 101926.

29. Zyada F, Sheta M, El Degwi H, and Saad R. Anxiety, depression and strain among caregivers of terminally ill patients. Egyptian Journal of Psychiatry $2013 ; 34(2): 77-84$. 